\title{
América Latina y el nacionalismo español. Alfonso XIII ante el movimiento hispanoamericanista $(1902-1929)^{1}$
}

\section{Latin America and Spanish Nationalism. Alfonso XIII and his Response to the Hispano-American Movement (1902-1929)}

\author{
Víctor Manuel Núñez García \\ (D) 0000-0003-1538-3369 \\ Universidad de Sevilla, España \\ victorm@us.es
}

\section{María Luisa Calero Delgado \\ (D) 0000-0002-1235-3693 \\ Universidad de Sevilla, España \\ mluisacalero@us.es}

Resumen: Dentro del imaginario nacionalista español desarrollado a finales del siglo xix y las primeras décadas del xx Latinoamérica y el incipiente movimiento hispanoamericanista va ganando un peso específico significativo, hasta desplegarse como un elemento fundamental tanto de consolidación interior como de proyección exterior. Para la corona y para las elites españolas las políticas de la memoria y la reactualización del pasado se convirtieron en vectores esenciales a la hora de generar sinergias positivas para concitar adhesiones y lealtades al proyecto nacionalizador. El objetivo del artículo se centra en el papel del monarca, Alfonso XIII, dentro del movimiento hispanista desarrollado a ambas márgenes del Atlántico durante su reinado. Para ello se analizarán las visitas reales de Alfonso XIII a territorios de la actual Andalu-

\footnotetext{
1 Una primera aproximación al tema en Núñez (2016, pp. 221-243).
} 
cía, sus conexiones con el movimiento hispanoamericanista y sus hipotéticas proyecciones hacia la consolidación del imaginario nacionalista español a través de una mirada renovada hacia América.

Palabras clave: Alfonso XIII; nacionalismo monárquico; hispanoamericanismo; visitas reales.

Abstract: Within the Spanish nationalist imaginary developed at the end of the 19th century and the early decades of the 20th century, Latin America and the incipient Hispanic-American movement acquired a significant specific weight, until they became a fundamental element of both internal consolidation and external projection. For the crown and the Spanish elites, the policies of memory and the updating of the past became essential vectors when generating positive synergies to attract adhesions and loyalties to the nationalizing project. The purpose of the article is to examine the role of the monarch, Alfonso XIII, within the Hispanic movement developed on both sides of the Atlantic during his reign. To this end, it analyzes the royal visits of Alfonso XIII to territories in present-day Andalusia, his connections with the Spanish Americanist movement and his hypothetical projections of the consolidation of the Spanish nationalist imaginary through a fresh look at America.

Key words: Alfonso XIII; monarchical nationalism; Spanish Americanism; royal visits.

Fecha de recepción: 19 de octubre de 2017 Fecha de aceptación: 9 de abril de 2018

\section{INTRODUCCIÓN. MONARQUÍA Y NACIÓN EN LA HISTORIOGRAFÍA ESPAÑOLA}

as líneas de investigación centradas en los procesos de construcción iden-
titarios y de formación de la colectividad española en clave nacionalista
han ocupado un lugar preferente durante las últimas décadas en la produc- 
ción historiográfica. ${ }^{2}$ Durante el siglo xIX se activan las primeras estrategias políticas para articular una identidad para el Estado-nación español (Álvarez, 2001), la etapa final del siglo xIx y los inicios del siglo xx se definen como un periodo de intensificación de estas estrategias que otorgan progresivamente un papel central a la monarquía y en concreto a Alfonso XIII desde el inicio de su reinado en 1902. El papel protagonista que el monarca logra adquirir, dentro de las múltiples y poliédricas aristas que la política nacionalizadora y de masas exigió a la corona en la época, igualmente ha sido un espacio para el análisis que ha suscitado un indudable interés. ${ }^{3}$ Por otra parte para el imaginario nacionalista español América Latina, el movimiento hispanoamericanista y la proyección de una mirada renovada hacia el continente americano se despliegan como elementos visibles y de utilidad a la hora de consolidar líneas políticas internas y la posición del país en la política exterior y en las relaciones internacionales. En concreto entre las estrategias para crear una cultura cohesiva a través de un relato nacional América ocupó un lugar preferente (Marcilhacy, 2010, 2013; Sepúlveda, 2005, 2013).

El enfoque de este estudio, acotado cronológicamente entre 1902 y $1929,{ }^{4}$ plantea la imbricación de tres elementos fundamentales: el hispanoamericanismo y el nacionalismo español, la monarquía y su relación con el binomio nacionalismo/americanismo y, en tercer lugar y desplegándose como hilo conductor analítico, la visita real a la región de Andalucía como uno de los espacios contextuales en los que se escenifica el papel y peso potenciales del monarca respecto al movimiento hispanoamericanista, poniendo de re-

${ }^{2}$ La historiografía española ha sido prolija en las últimas décadas a la hora de abordar el nacionalismo español. De entre lo mucho publicado se pueden consultar: (Beramendi, Máiz y Núñez, 1995; Granja, Anguera y Beramendi, 2001; Morales, Fusi y De Blas, 2013; Moreno, 2007; Taibo, 2007).

${ }^{3}$ Alfonso XIII como sujeto/actor histórico relevante en su época y en su entorno social ha generado una atención constante por parte de la historiografía contemporaneista española. Sin ánimo de ser exhaustivos por el volumen ingente de la producción historiográfica sobre el personaje la obra Alfonso XIII. Un político en el trono logra abordar desde múltiples ángulos y perfiles temáticos la dimensión política del monarca (Moreno, 2003a).

Respecto al análisis de la labor y papel de Alfonso XIII enhebrando cuestiones como la corona y la nacionalización de España, la corona y la política de masas, la corona y el regeneracionismo o el desarrollo del concepto monarquía escénica (Moreno, 2013a, pp. 319-348); (Moreno, 2013b, pp. 107-126). Igualmente interesante resulta el trabajo de Gemma Rubí respecto a la relación de Alfonso XIII con Cataluña (Rubí, 2013, pp. 67-78).

${ }^{4}$ El segmento cronológico seleccionado se extiende desde el inicio del reinado hasta la celebración de la Exposición Iberoamericana de Sevilla de 1929. 
lieve su destacada dimensión regional y local. En puridad, la presencia de Alfonso XIII en los actuales territorios de la comunidad autónoma de Andalucía en visitas oficiales y en estancias privadas mostró un carácter constante a lo largo de su reinado. ${ }^{5}$ Andalucía, al igual que otras regiones españolas, se convirtió en diferentes momentos en un foco de interés, de preocupación y en un ámbito fértil para desarrollar ciertas líneas políticas beneficiosas para la corona y el gobierno central. Por un lado, hambrunas, crisis de subsistencia, desarrollo del movimiento obrero y del republicanismo político, o la necesidad de implementar en Andalucía el regeneracionismo y, por otro, celebraciones, conmemoraciones y efemérides tales como las relacionadas con el movimiento americanista llegan a confluir en ejes vertebradores desde un primer plano o una posición de trasfondo en las diversas visitas oficiales del monarca a Andalucía.

Por tanto, tomando como hilo conductor fundamental las visitas oficiales de Alfonso XIII (el Rey Regenerador) a Andalucía, ${ }^{6}$ cuestiones como la monarquía y el nacionalismo; el potencial papel de la corona como elemento cohesionador de la nación española e incluso de proyección internacional; la simbología, ceremonias, ritualidad y los mitos desplegados durante la visitas oficiales como medios de consolidación del discurso hegemónico e imaginario nacionalista; conceptos como la monarquía escénica, el ceremonial, teatral -performing monarchy- (Moreno, 2013a), welfare monarchy o la monarquía banal (Billing, 1995; Moreno, 2013a, p. 330) serán abordados a través de este estudio para plantear líneas de debate que relacionen estos elementos con el movimiento hispanoamericanista. Ciertamente los límites entre la historia política y la historia cultural se difuminan a la hora de calibrar la importancia del contenido simbólico de acontecimientos, ceremonias y rituales como los monárquicos, convirtiendo a estas manifestaciones en elementos de análisis

${ }^{5}$ Como precisión metodológica este artículo analiza exclusivamente la visita regia oficial dejando al margen la dimensión privada de las visitas de Alfonso XIII a Andalucía, muy habituales, por otra parte, dentro de su reinado en relación con actividades cinegéticas, celebraciones taurinas y diversas actividades de ocio. Incluso dentro de la visita oficial habría que distinguir la agenda pública y los actos privados, muy necesarios dentro de la sociedad clientelar donde se estrechaban las relaciones de poder formal e informal entre el monarca y las elites locales, en unos espacios de sociabilidad en los que las relaciones de carácter clientelar marcan la pauta y donde el monarca podía complementar la dispensa de favores localistas "comprometidos" en la visita oficial, con favores particulares a escala para las elites en estas estancias privadas.

${ }^{6}$ Entre las crónicas y los relatos coetáneos sobre las visitas oficiales de Alfonso XIII a Andalucía destacan Alfaro (1921); Gaona (1904) y Urbano (1904). 
dentro de la realidad política (Canal y Moreno, 2009). Respecto a las fuentes utilizadas en el presente estudio predominan las de naturaleza hemerográfica, tanto la prensa política andaluza como las publicaciones de marcado carácter hispanoamericanista (especialmente La Rábida), y respecto al análisis de los viajes reales las crónicas coetáneas, redactadas desde el encargo oficial de palacio o no, igualmente reproducen el discurso hegemónico de la monarquía española, con sus potencialidades de análisis desde la historia cultural.

La puesta en escena del poder material y del poder simbólico en las visitas reales, fundamentalmente respecto al papel de las elites locales, muy implicadas en el hispanoamericanismo, establecen un nuevo clima de relaciones constructivas entre los objetivos de las elites en los territorios y las vinculadas a los poderes centralizadores del Estado, donde el interés por participar activamente en los diferentes elementos de la escenificación simbólica de la monarquía banal a través de las visitas oficiales de Alfonso XIII, contribuye a consolidar el ya citado discurso hegemónico e imaginario nacionalista español. En Andalucía en concreto, dentro de los diversos objetivos de cada visita, las celebraciones de eventos asociados al movimiento hispanoamericanista se convirtieron potencialmente en elementos preferentes en mayor o menor medida dependiendo de cada caso. Más aún, se podría definir dicho movimiento como la gran empresa cultural del nuevo españolismo regeneracionista encarnado en la figura del monarca (Moreno, 2013a, p. 336), con relevantes conexiones hacia la proyección del país en el exterior como se ha apuntado. ${ }^{7}$

\section{LA ESCENIFICACIÓN DE LAS VISITAS REGIAS EN ANDALUCÍA. LUGARES COMUNES, SÍMBOLOS, RITOS Y CEREMONIAS}

Alfonso XIII a lo largo de su reinado viajó de manera sistemática por todas las regiones españolas para popularizar su figura y establecer contacto no sólo con las autoridades y las elites locales, sino especialmente con las clases populares (Rubí, 2013, p. 69), práctica ya habitual en las monarquías de la época (Moreno, 2013a, p. 342). Como apunta Moreno (2013a) las giras reales cons-

${ }^{7}$ Las recientes investigaciones de David Marcilhacy han diversificado el enfoque analítico respecto al movimiento hispanoamericanista en la España de la Restauración (Marcilhacy, 2010, 2013, pp. 501-524). 
tituyeron el principal medio empleado para que la corona echara raíces. Al igual que su padre en sus inicios en el trono, el joven monarca dedicó mucho tiempo a conocer el país y especialmente a ser conocido y estar cercano para la población (p. 331). Aunque sus antecesores ya practicaron la visita oficial, la manera en la que Alfonso XIII concibió este contacto directo con el pueblo fue una novedad en la realeza española; se trataba básicamente de la adaptación de la monarquía -una institución en principio instalada en las tradiciones- ${ }^{8}$ a la política de masas que se está consolidando.

La primera década del reinado de Alfonso XIII, desde 1902 hasta 1913, se caracteriza por la gran intensidad de las actividades del monarca como agente nacionalizador a través de los rituales y las ceremonias puestos en liza fundamentalmente en los actos monárquicos, los eventos militares y los viajes regios. ${ }^{9}$ Para el fortalecimiento y consolidación del binomio monarquía-nación y del papel preponderante de la corona como ente político en la nueva democracia liberal española era fundamental el papel del joven monarca. Durante esta primera etapa coincidieron circunstancias como la trayectoria emergente de los grupos políticos republicanos, de movimientos nacionalistas como el catalán y el propio fortalecimiento del nacionalismo español en forma de proyecto regeneracionista tras el desastre del 98, en el que el Rey Regenerador ocupaba un espacio protagónico destacado. Por tanto, el viaje regio en forma de visitas oficiales se diseñó y planificó desde los gobiernos de turno y desde palacio como una estrategia de primer orden. No olvidemos que Alfonso XIII rara vez hacía o decía algo en público que no hubiera planificado y aprobado el ejecutivo; además en general los programas de actividades en las visitas reales eran muy similares para todas las regiones españolas y respondían a una planificación supervisada al detalle desde palacio, más allá de que las encargadas de la organización y la correcta ejecución fuesen las autoridades locales y provinciales de cada lugar. El propio Alfonso se mostraba consciente de la importancia de esta estrategia al aconsejar a Manuel II de Portugal reco-

${ }^{8}$ Monarquía y nación pertenecen a priori a universos políticos diferentes: el de la tradición y el de la modernidad (Moreno, 2013a, p. 320).

${ }_{9}$ Las visitas oficiales se iniciaron de manera recurrente en mayo de 1902. Al finalizar el año 1904 a excepción de las Islas Canarias, que aguardarían tras varios retrasos hasta 1906, el monarca prácticamente ya había visitado la totalidad de los territorios españoles. Tras este periodo de visible intensidad, a partir de 1906 las visitas serán más distanciadas pero continuarán como un importante instrumento de nacionalización. 
rrer regularmente su país con el fin de "mete(rse) a los portugueses en el bolsillo" (Moreno, 2013a, pp. 324, 326 y 332).

En concreto, la presencia de la monarquía española en territorios andaluces a través del viaje regio oficial y de otras tipologías se manifiesta con una cierta regularidad durante el siglo xIx aunque sin la asiduidad del Rey Regenerador a comienzos del siglo xx. Isabel II realizó un importante viaje en el año $1862,{ }^{10}$ además de un breve periodo de "exilio" sevillano en 1876, y Alfonso XII visitó de manera oficial Andalucía en marzo de 1877, viajó a Huelva y a la cuenca minera de Riotinto en 1882 y a las zonas afectadas por el terremoto de diciembre de 1884 en las provincias de Granada y Málaga (Utrera, 1999, pp. 181 y 184). Sus visitas a Sevilla en diciembre de 1877, durante los trabajos de preparación de la boda real con María de las Mercedes, y en abril de 1879, ya bajo el luto por su primera esposa y por la infanta Cristina de Orleans, pueden considerarse dentro del ámbito privado. ${ }^{11}$ En la ciudad de Sevilla, en total, se produjeron trece estancias de miembros de la familia real entre 1810 y 1879: cuatro monarcas, dos reyes consortes y dos princesas de Asturias (Fernández, 2005).

Andalucía fue una de las regiones del país que contaría más regularmente con la presencia de Alfonso XIII, tanto en viajes oficiales como en visitas privadas relacionadas con el ocio y el esparcimiento. Dentro del esfuerzo realizado a comienzos de su reinado por conocer y ser conocido en la mayoría de las regiones del país, en mayo de 1904 tras un periplo que le había llevado a Baleares, Ceuta, Melilla y Chafarinas llegó a tierras andaluzas para visitar, entre otras, Cádiz, San Fernando, Jerez, Sevilla, Huelva, Córdoba, Jaén, Málaga, Almería, Granada... Tras un laborioso viaje de 40 días Alfonso XIII llegó a afirmar: "se me debía conceder la jornada de ocho horas" (Fernández, 1977, p. 52; Moreno, 2013a, p. 332). Aparte de esta primera visita tenemos constancia de estancias oficiales en Sevilla (1905 -boda de la infanta María Teresa con Fernando Ma de Baviera-, 1906, 1909, 1914, 1925 y 1929), ${ }^{12}$ Málaga (1904 -mes de junio-, 1921 -inauguración de las obras de la presa del duque de Guadal-

${ }^{10}$ Sobre los viajes reales de Isabel II aparte del caso andaluz, véase Barral (2012); Carasa (2007); Núñez (en prensa).

${ }^{11}$ La tesis doctoral de María del Carmen Fernández Albéndiz nos proporciona una visión panorámica y analítica de la evolución del fenómeno de la visita regia a la ciudad de Sevilla desde comienzos del siglo xIx hasta la época de Alfonso XII (Fernández, 2005, 2007).

${ }^{12}$ Además habría que añadir las visitas regulares del monarca a la ciudad de Sevilla para la supervisión de las obras para la Exposición Universal Iberoamericana de 1929. Concretamente desde 1909 hasta 1929 Alfonso XIII visitó Sevilla en 32 ocasiones (Braojos, 1992, p. 137). 
horce- y 1922), Granada (1909 y 1917), Jaén (1929 -visita de las obras del pantano de Jándula-), Cádiz (1924 y 1930) o en Huelva (1915, 1926 -regreso de la tripulación del Plus Ultra- y 1929 -visita a la Gruta de las Maravillas en Aracena-), entre otras (Fernández, 1977; Utrera, 1999, pp. 181-182).

Como puntualiza Gemma Rubí, el formato de las visitas reales de la primera época del reinado fue muy similar en la inmensa mayoría de los casos (Rubí, 2013, p. 71): recibimiento apoteósico en el apeadero del ferrocarril o en el puerto si la llegada se produce por vía marítima, al son de los acordes de la "Marcha real" y de salvas militares; recepción protocolaria de las máximas autoridades políticas, militares $y$, en algunos casos, religiosas; desfile triunfal por las calles engalanadas y abarrotadas de la población, visita de la catedral o iglesia principal de turno, tedeum; visitas protocolarias al Ayuntamiento, diputación, gobierno civil... Todo ello como antesala de una apretada agenda de visitas, recepciones, banquetes, actos religiosos, militares, culturales, en la mayoría de las ocasiones con el necesario aderezo de la presencia masiva de las clases populares.

La puesta en escena del ritual del viaje, más allá de su pertinencia o de su eficacia en cada caso, desplegaba una serie de elementos o de lugares comunes reproducidos repetitivamente dentro del canon de la visita oficial; estos viajes seguían unas pautas preestablecidas que se perfeccionaron con el tiempo y la experiencia. Entre ellos: la vertiente religiosa, la militar -que en ocasiones podía a llegar a ocupar una parte muy importante del programa de la visita-, el populismo y el contacto con las clases populares, el papel de las autoridades y las elites locales de cada localidad visitada o la vertiente cultural, académica y deportiva.

El aspecto religioso en los viajes regios era fundamental y se le otorgaba un papel central dentro de la escenificación del ritual de la visita. El primer evento en todos los casos, tras la llegada a una localidad de la comitiva regia y la correspondiente recepción, es el desplazamiento a la catedral o iglesia principal para asistir a un tedeum, misa solemne de acción de gracias (Moreno, 2013a, p. 333). El monarca entraba y salía de los templos bajo palio, y era habitual que realizara ofrendas a los patrones y vírgenes locales; a su vez el obispo o cura párroco solía responder con algún tipo de presente religioso, y fue muy usual el nombramiento de Alfonso como hermano mayor de todo tipo de cofradías religiosas. Alfonso XIII durante su visita a Roma de 1923 ya transmitió al papa Pío XI una apasionada profesión de fe americanista, mos- 
trando la representación del papel simbólico de España respecto a América desde la "reconquista espiritual" (Marcilhacy, 2010, pp. 500-501).

En Andalucía durante las presencias del monarca en las celebraciones relacionadas con los lugares colombinos, siempre se programaba como acto inaugural el habitual tedeum ofrecido en el patio del convento de La Rábida, impregnando al acto de evidentes simbolismos históricos y religiosos, como en el caso de la llegada de la tripulación del hidroavión Plus Ultra a Huelva en $1926 .{ }^{13}$ En esa misma estancia también se programó la visita a las escuelas religiosas del Sagrado Corazón dirigidas por Manuel Siurot. El propio Siurot, activo miembro de la Sociedad Colombina Onubense, expuso al monarca que los principios esenciales en sus escuelas eran "Jesucristo, España, El Rey y América”, expresando de manera muy sintética el papel central que ocupaba Alfonso XIII para el movimiento hispanoamericanista durante las primeras décadas del siglo $\mathrm{xx} .{ }^{14}$ Por otra parte, a través de las ceremonias religiosas castrenses como el caso de las misas de campaña, se establecía un vínculo directo con otra de las vertientes fundamentales en la visita regia: la militar.

El trayecto biográfico de Alfonso XIII muestra significativamente el papel central que el ámbito militar suponía en su cosmovisión vital y patriótica. El monarca fue educado como un soldado y en los campamentos militares se sentía entre los suyos; además, la Constitución lo señalaba como jefe de las fuerzas armadas (Moreno, 2013a, p. 339), papel que se escenificaba con gran profusión en las visitas regias. Los militares, muy sensibles en el aspecto simbólico, se erigieron en custodios de la unidad patria en esta época de manera muy visible, además alentaron tareas nacionalizadoras a las que se unió el rey (Moreno, 2013a, pp. 339-340). El programa de la visita real establecía en el protocolo que el monarca utilizase el uniforme de almirante de la armada -incluidos símbolos externos del poder de su dinastía como la banda de Carlos III y el toisón de oro- o de capitán general a su llegada a una nueva localidad, al menos en la primera etapa del reinado. En todo caso la indumentaria civil también fue habitual en las jornadas donde no había programados eventos de carácter militar. A su llegada a territorios andaluces procedente del norte de África en 1904 el ritual del recibimiento incluía la escolta propia, la de otros

13 Fecha memorable. La Rábida. Revista Iberoamericana, núm. 141, 1926, pp. 8-9. Repositorio de la Universidad Internacional de Andalucía (en adelante UNIA), España, http://dspace. unia.es. Una reciente visión interdisciplinar sobre el vuelo del Plus Ultra en Márquez (2016).

${ }^{14}$ El Rey en las Escuelas del Sagrado Corazón de Huelva. La Rábida. Revista Iberoamericana, núm. 142, 1926, pp. 15-16. Repositorio UNIA, España http://dspace.unia.es 
buques de la armada española e internacionales (británicos, portugueses, franceses o alemanes), salvas militares y la interpretación de la "Marcha real". El programa de las visitas generalmente incluía desfiles, revistas, visitas a cuarteles, academias militares, arsenales y, en definitiva, a todo tipo de instalaciones militares. Otro de los lugares comunes de las crónicas de dichas visitas suele hacer hincapié en la cercanía y llaneza del monarca a la hora de inspeccionar instalaciones militares, en las que se muestra cercano al mezclarse con los reclutas, al interesarse por su vida cuartelaria o compartiendo el rancho. ${ }^{15}$

El simbolismo nacionalista entre otros elementos presentes en los viajes regios se expresaba a través de la onmipresencia de los colores nacionales, la "Marcha real" y el escudo real. La "Marcha real" no sólo se interpretaba a la llegada a puerto o a la estación de ferrocarril, sino que estaba presente en todas las actividades programadas en cada jornada de la visita de manera repetitiva, interpretada tanto por bandas de música militares como civiles. Los adornos y la arquitectura efímera (arcos, templetes...) se despliegan también como elementos indispensables en la puesta en escena de la visita regia, de esto se era perfectamente consciente en las localidades receptoras donde las inversiones a la hora de dar un aspecto de gala a cada localidad en cuestión (limpieza, arquitectura efímera, iluminación, fuegos de artificio, erección de algún tipo de placa o monumento...) llegan a sobrepasar las capacidades presupuestarias de las instituciones locales y provinciales ${ }^{16}$ Los colores de la bandera nacional se muestran constantemente tanto en la arquitectura efímera como en otros muchos elementos, por ejemplo durante la visita de 1904 las autoridades de Huelva recomendaron a las mujeres pertenecientes a la comitiva receptora del monarca en La Rábida llevar lazos y cinturones con los colores nacionales. ${ }^{17}$

Como apunta Gemma Rubí en su estudio de las visitas regias a Cataluña, la corona despertaba un fuerte halo de seducción, de fastuosidad y magnificencia, que se potenciaba precisamente escenificando su presencia entre las

${ }^{15}$ La importancia de los actos militares puede verse reflejada en la llegada de efectivos militares procedentes de Sevilla a la ciudad de Huelva en 1904 para participar en la parada militar organizada al efecto. La Provincia, Huelva, 4 de mayo de 1904.

${ }^{16}$ En el caso de Málaga una parte importante de los gastos de la visita fueron sufragados por la familia Larios, en Huelva el Ayuntamiento en sesión plenaria aprobaría las cuentas de la visita del rey a la ciudad con oposición del grupo republicano (Urbano, 1904); La Provincia, Huelva, 6 de mayo de 1904.

${ }^{17}$ La Provincia, Huelva, 6 de mayo de 1904. 
masas. Como ocurre en la actualidad, se veía obligada a rediseñar constantemente su papel en la sociedad -en la nueva sociedad de masas-, reforzando los signos exteriores de su poder (Rubí, 2013, p. 67). Los diferentes relatos de las visitas dan muestra de un populismo y de un apoyo popular inquebrantable e incluso delirante, otorgando un papel central a niños, estudiantes universitarios y mujeres (Gaona, 1904; Urbano, 1904). En el otro extremo encontramos al rey, muy joven en sus primeras visitas, como una persona cercana que no rehúye mezclarse entre la multitud: unas veces en coche de caballos, otras veces en automóvil y otras -cuando la ocasión lo requería- a caballo.

La cuestión relacionada con la beneficencia y los donativos económicos con los que el monarca y sus acompañantes se prodigaban en las visitas también resulta un aspecto destacable. Los donativos económicos para necesitados y proyectos de carácter benéfico añadían una nueva característica a la imagen que se perfila del monarca en los relatos y las crónicas de las visitas: la generosidad. Estas donaciones económicas se llevaban a cabo usualmente al abandonar cada localidad. Como ejemplo, en su visita a Huelva el monarca donó 300 pesetas para los marineros que habitaban en la almadraba "Las Torres"18 o la donación de 1000 pesetas a las Hermanitas de los Pobres en Cádiz. ${ }^{19}$ En esta línea, no faltaron visitas a hospitales y a la Cruz Roja, a la Facultad de Medicina y al Hospital Provincial de Cádiz (Gaona, 1904, pp. 2931), y a asociaciones benéficas para desarrollar la imagen del rey compasivo, aunque también fue habitual que dejase esta parte de las visitas en manos de las mujeres de la familia real. La visita real se presentaba además como una ocasión propicia para que instituciones y miembros de las elites locales se destacasen complementando estos gestos de generosidad. Así durante la visita a Huelva del 6 y 7 de mayo de 1904 el senador por la provincia, Juan Mateos Jiménez, donó 1000 pesetas en bonos de comidas para pobres; el Ayuntamiento y la diputación igualmente sufragaron una limosna y la sucursal del Banco de España distribuyó a través de la Asociación de la Caridad 500 panes de medio kilo y 500 raciones de chorizo entre los necesitados. ${ }^{20}$ En definitiva, nadie debía pasar hambre durante el feliz evento de la estancia del monarca en cada localidad.

18 La Provincia, Huelva, 10 de mayo de 1904.

19 El cronista de la visita a Cádiz de 1904 nos presenta pormenorizadamente el reparto y destinatarios de un monto total de 5000 pesetas que Alfonso XIII donó en la ciudad gaditana (Gaona, 1904, p. 54).

${ }^{20}$ La Provincia, Huelva, 4 de mayo de 1904. 
Otro de los aspectos a destacar en las visitas reales es la presencia y protagonismo de las elites autóctonas y de las instituciones locales y provinciales. Como ya se ha comentado aun desde la supervisión de palacio las instituciones locales y sus elites se convierten en agentes centrales a la hora de organizar y patrocinar las visitas reales en sus localidades. Los poderes civiles, por tanto, rendían pleitesía a los visitantes, pero como contrapartida ocupaban espacios privilegiados en la escenificación de la visita, en la que alcaldes, diputados provinciales, gobernadores civiles e incluso los representantes parlamentarios de la provincia en cuestión se hacían visibles junto al monarca. En este sentido, aparte de que estos cargos políticos ocupasen lugares destacados en la recepción y en los diversos actos programados, fue muy habitual que ayuntamientos y diputaciones organizasen en sus instalaciones banquetes y cenas oficiales. ${ }^{21}$ No sólo las elites de la política institucional se hacían visibles, los notables o caciques de cada localidad, fundamentales en el sistema político restauracionista, igualmente ocupan espacios simbólicos de poder en los diferentes rituales de las visitas, un ejemplo muy significativo fue el destacado protagonismo de la familia Larios en la visita regia a Málaga de 1904. Con estas estrategias se reafirmaban las atribuciones de estos actores históricos como intermediarios entre los ciudadanos y el Estado (Moreno, 2013a, 333) (véase imagen 1).

En definitiva los grupos de poder de los diferentes enclaves del territorio nacional están muy interesados en que el monarca visite sus localidades y en tener un papel visible en dichos eventos. En relación con ello en las intensas agendas de las visitas regias de Alfonso XIII también encontraron hueco ámbitos de sociabilidad y de asociacionismo de carácter burgués: ${ }^{22}$ sociedades económicas de amigos del país, casinos, centros cívicos... ${ }^{23}$ Además, también fue usual que se visitasen los principales centros económicos y de desarrollo de cada localidad, vinculando la imagen del monarca al progreso nacional. Desde un taller industrial en Huelva, una constructora naval y la Compañía Trasatlántica en Cádiz, hasta la visita a las principales industrias

${ }^{21}$ Durante la visita oficial a Huelva y los lugares colombinos de 1926 los banquetes y cenas tuvieron lugar en el Círculo Mercantil, Diputación Provincial y Hotel Colón. Fecha memorable. La Rábida. Revista Iberoamericana, núm. 141, 1926, pp. 8-9, uniA, España http://dspace.unia.es

${ }^{22} \mathrm{Al}$ igual que con las cofradías religiosas el rey solía aceptar durante las visitas la presidencia honorífica de todo tipo de asociaciones.

${ }^{23}$ La visita al casino gaditano puso punto final a la primera jornada del monarca en su visita a Cádiz de 1904 (Gaona, 1904, p. 37). 


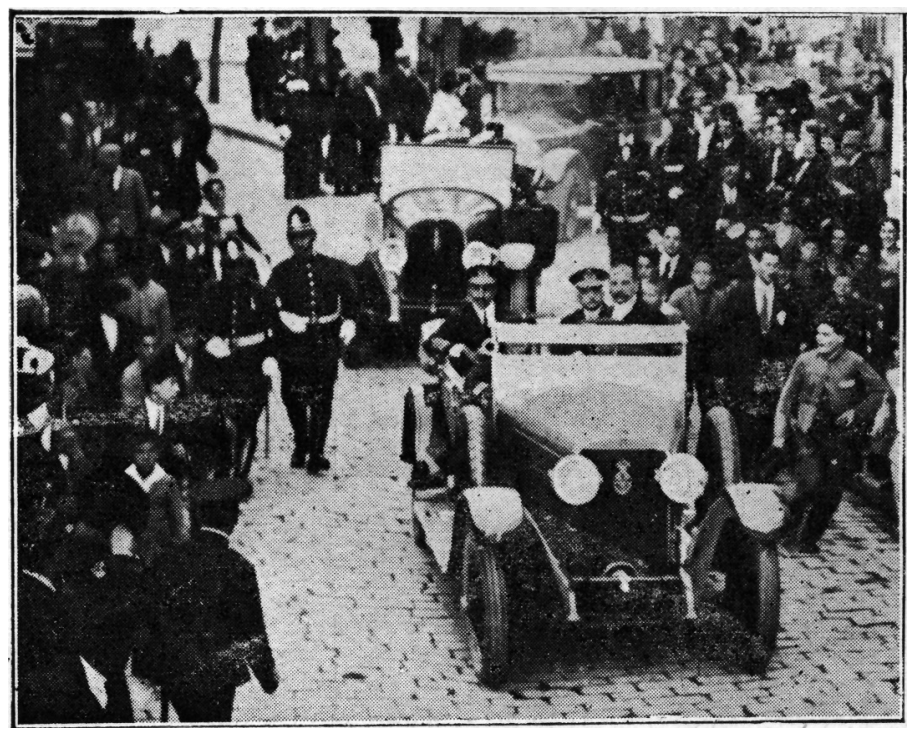

Imagen 1. Alfonso XIII en coche acompañado del ministro de Marina y del alcalde de Huelva durante su visita a la ciudad con motivo de la recepción de los aviadores del Plus Ultra (1926). Fuente: La Rábida. Revista Iberoamericana, núm. 141, 1926, p. 13. Recuperado de http:// dspace.unia.es/handle/10334/3061 Repositorio de UNIA.

de Málaga: fábrica de azúcar La Zamarrilla, Industria Malagueña de los Larios, la destilería de los señores Jiménez y Lamothe o los altos hornos de la familia Heredia. ${ }^{24}$

Por otra parte, la visita real se percibía como una ocasión propicia para solicitar favores, reclamar ayudas para ejecutar proyectos, o mejoras relacionadas con logros colectivos o desde intereses más particulares. Estas peticiones se realizaban constante y tenazmente en todas y cada una de las jornadas de las visitas reales, unas veces a través de las elites locales, el Ayuntamiento, la diputación, la Cámara de Comercio o la Sociedad Económica de Amigos del País de la zona y en otras ocasiones estas peticiones se llevaban a cabo desde las propias clases populares con los instrumentos que tenían a su alcance. Respecto a las peticiones más oficiales e institucionalizadas el alcalde de Cádiz saludaba al monarca señalando "que nosotros sólo podemos desear y

${ }^{24}$ La Provincia, Huelva, 10 de mayo de 1904; Gaona (1904, pp. 52-53); Urbano (1904). 
decir ¡Viva el rey!, y él puede hacer que Cádiz viva” ${ }^{25}$ En Granada en un arco triunfal se recogían las principales peticiones, entre ellas pantanos, caminos vecinales, carreteras, canales, líneas de ferrocarril o una escuela de agricultura ${ }^{26}$ En Huelva el Ayuntamiento, la junta de obras del puerto o la Cámara de Comercio solicitaron un nuevo cuartel, una escuela graduada o la llegada a Huelva de trenes mixtos. ${ }^{27}$ En Málaga, aparte de importantes obras para la ciudad que el propio monarca inauguró, su Cámara de Comercio propuso la creación de una "zona neutra" que atrajese nuevos negocios a la zona portuaria (Urbano, 1904). Todas estas peticiones, memorias y escritos se archivaban por parte de los representantes del gobierno. Más allá del nivel de cumplimiento de lo que se le solicitaba al monarca en la época, la visita regia de Alfonso XIII se contemplaba como una potencial opción para materializar ciertas aspiraciones.

Estos lugares comunes se complementaban a su vez con una serie de eventos de tipo cultural, artísticos, académicos, etnográficos o deportivos mostrando la faceta más ociosa de la agenda de las visitas oficiales. Así, también tuvieron cabida espectáculos taurinos, regatas marítimas, conciertos, obras de teatro, visita a museos, recreación de fiestas regionales o espectáculos. En suma, la escenificación de la visita real a través de los lugares comunes analizados tanto en territorios andaluces como en los del resto del país se caracterizó por una planificación precisa y bien estudiada, donde la figura del monarca adquiere un papel central. Entre 1902 y 1929 varias de las visitas regias oficiales de Alfonso XIII a territorios andaluces presentan como denominador común el protagonismo de actos y conmemoraciones relacionadas con el desarrollo del ideal de raza hispánica y con el movimiento hispanoamericanista, para los que resultaban esenciales el rey y la puesta en escena de la monarquía banal.

${ }^{25}$ La ciudad de Cádiz solicitó la ejecución del proyecto de obras de su puerto, la libre edificación en extramuro para el ensanche de la ciudad y medidas proteccionistas para su industria naval (Gaona, 1904, pp. 6 y 48-49).

${ }^{26}$ El Año Político, Madrid, 29 de abril de 1904. En Moreno (2013a, p. 334).

${ }^{27}$ La Provincia, Huelva, 4 y 6 de mayo de 1904. 


\section{LA ESTRATEGIA POLÍTICA DE LA VISITA REGIA. ALFONSO XIII Y EL HISPANOAMERICANISMO COMO ELEMENTO DE REGENERACIÓN NACIONAL}

Desde el punto de vista del binomio monarquía/nacionalismo se le otorga importancia a la reactualización del pasado (Moreno, 2013a, p. 336). La instrumentalización de la historia y la potenciación de ciertos episodios que previsiblemente generarían sinergias positivas a la hora de concitar adhesiones y lealtades al proyecto nacionalizador, se implementaron como elementos convenientes en la planificación y escenificación de la visita real. Además, la búsqueda en el pasado de glorias pretéritas para celebrar fue uno de los rasgos del movimiento regeneracionista. Entre los elementos simbólicos que identifican la proyección nacional desde un punto de vista endógeno y de cara a la percepción exterior, los identificadores míticos de naturaleza historicista adquieren mucha importancia en la consagración de la idea nacional, y entre ellos cabría destacar los discursos históricos fundacionales y, especialmente, la creación de un sistema de referencias e hitos históricos reconocibles por la comunidad (Sepúlveda, 2002). Como puntualiza Moreno (2003b) uno de los instrumentos nacionalizadores de mayor peso en las primeras décadas del siglo $\mathrm{xx}$ se encuentra en las políticas de la memoria, en las que destacan las conmemoraciones que inundaban la época y que desembocaron en la celebración de cientos de actos públicos vinculados a gran diversidad de efemérides relacionadas con el pasado nacional. Entre 1890 y 1920 diversas efemérides en forma de centenario reclamaron el apoyo oficial y la adhesión de la población: el IV centenario del descubrimiento de América, el levantamiento del 2 de mayo y los sitios de Zaragoza, diversas batallas y héroes de la guerra de Independencia, la batalla de Covadonga, el levantamiento de Riego, Velázquez, Cervantes, el descubrimiento del Pacífico... (Moreno, 2003b, pp. 208-209).

En torno a estas conmemoraciones se vislumbra el interés por crear relatos históricos que legitimen a los poderes presentes y que perfilen el marco histórico necesario para fortalecer los discursos nacionalizadores donde los mitos, los símbolos y los rituales podían resultar de utilidad, todo ello matizado por las visiones e intereses de los diferentes grupos políticos dominantes. En puridad el recuerdo de personajes heroicos y de fechas clave en la creación de una historia nacional cumple una misión de primer orden en el arranque y consolidación de las identidades nacionales. A través de las políticas de la memoria y de las conmemoraciones la mitología nacionalista 
se consolida, se transforma y se pone al día (Moreno, 2009, p. 124). Una cuestión de calado sería la siguiente: ¿hasta qué punto la institución monárquica estuvo implicada en la potenciación de estos eventos rentabilizándolos con la presencia de Alfonso XIII o, por el contrario, fueron las diferentes comisiones organizadoras con protagonismo de las elites locales las que solicitaron con insistencia la participación de la casa real y del monarca ${ }^{28}$ Posiblemente ninguno de los dos extremos nos proporcione un marco explicativo útil y sea mucho más enriquecedor analizar los términos medios, en clave de intereses, ideas y proyectos comunes.

Aunque desde un enfoque meramente hispanoamericanista, tanto en la formación y desarrollo del movimiento como en la organización de actos y conmemoraciones se produce un desarrollo desde abajo hacia arriba, tesis defendida por D. Marcilhacy y confirmada desde el caso andaluz (Marcilhacy, 2013, pp. 515-516). La base del movimiento fue muy diversa (políticos, empresarios, intelectuales, profesiones liberales, profesores...), partiendo de que tras el desastre del 98 con la consecuente claudicación del estatus de metrópoli en el continente y en pleno desarrollo de una nueva política -política de masas-, desde posturas regeneracionistas e incluso krausistas a escala educativa la idea de América y del fortalecimiento de lazos de una comunidad atlántica hispanoamericana se fomentó en las clases populares, desde un prisma nacional donde para las elites y, por qué no, para la monarquía apelar al patriotismo y estimular el ardor identitario de los españoles supuso una estrategia para la salvaguarda del régimen (Marcilhacy, 2013, p. 506). Como ejemplo de desarrollo de abajo hacia arriba, incluso desde la periferia hacia el centro o desde el exterior al interior, cabría destacar la consolidación en la década de 1910 de la fiesta nacional del 12 de octubre -fiesta de la Raza- gracias a la iniciativa de la sociedad civil, en la que participan tanto elites provinciales, líderes de opinión local, prensa o asociaciones americanistas, como colectivos de emigrantes desde las repúblicas latinoamericanas. ${ }^{29}$ Las elites políticas erradicadas del centro de las decisiones del Estado y cercanas a la monarquía, bajo la personificación simbólica de la idea de nación en Alfonso XIII, se adhieren progresivamente con posterioridad a un proceso que parte

${ }^{28}$ Un ejemplo ilustrativo podría ser la insistencia de las autoridades gaditanas de cara a la presencia del rey en las celebraciones del centenario de la Constitución de 1812 y de las Cortes de Cádiz. Véase Mateos (2003, pp. 171-192); Pecci y Moreno (2012, pp. 181-196).

${ }^{29}$ Este investigador dedica varios capítulos en su monografía al análisis de los orígenes de la fiesta del 12 de octubre en España (Marcilhacy, 2010). 
de la afirmación local y regional, e incluso transnacional desde la emigración española en América (Marcilhacy, 2013, p. 216).

En referencia a Andalucía y a estas políticas de la memoria, la relación histórica entre la antigua corona de Castilla y el continente americano a través de hitos como el descubrimiento -que se tenía por la mayor aportación de España a la historia de la humanidad-, la colonización o la herencia histórica y cultural compartida, sirvió de base para reelaborar y potenciar el relato de un pasado común, beneficioso para el fortalecimiento del discurso nacionalizador español y la búsqueda de un nuevo lugar en la política internacional para el país, como interlocutor y mediador entre los intereses europeos y los de América Latina. Los últimos años del xix traen consigo una experiencia positiva en cuanto al acercamiento del Estado español a América, el IV centenario, y otra traumática, las últimas pérdidas coloniales en 1898. Tras el desastre del 98 se hallaba de nuevo en duda la personalidad de España, incluso su propia existencia, por lo que se hacía urgente la redefinición de una nueva estrategia internacional coherente, por ello los esfuerzos se centraron en tender puentes hacia América para formar una comunidad moral hispanoamericana que diera relevancia mundial a España (Moreno, 2003a, pp. 215-216), dando origen al movimiento hispanoamericanista en el que se trataba de enlazar a través de este ideal colectivo la regeneración interna y la política exterior (Moreno, 2009, p. 135). ${ }^{30}$

Durante las dos últimas décadas del siglo xix y las primeras del xx el auge del movimiento asociacionista, con especial relevancia de instituciones como la Sociedad Colombina Onubense (Huelva, 1880), la Unión Ibero-Americana (Madrid, 1884), la Unión Ibero-Americana en Vizcaya (Bilbao, 1906) o la Casa de América (Barcelona, 1911), y la proliferación de publicaciones especializadas en temas americanistas vinculadas usualmente a estas asociaciones, ${ }^{31}$ muestran el éxito de una iniciativa que, partiendo de una herencia

30 Para la colectividad española América simboliza una proyección exterior halagadora, donde el pasado de la colonización americana se articuló como una potente referencia (Marcilhacy, 2013, p. 503). Desde una visión más clásica véase Pike (1971).

${ }^{31}$ Revistas como Unión Ibero-Americana (1886-1936) órgano de comunicación de la asociación del mismo nombre o La Rábida. Revista Colombina Iberoamericana (1911-1933) al amparo de la Sociedad Colombina Onubense. Otras importantes publicaciones de perfil americanista fueron La Ilustración Española e Hispanoamericana (1870-1921), Cultura Hispanoamericana (19121925), Boletín del Centro de Estudios Americanistas (1913-1925) o pioneras como Revista Española de Ambos Mundos (1853-1855), La América (1857-1874 y 1879-1866), El Museo Universal (1857-1869), Revista Hispanoamericana (1881-1891)... (Sepúlveda, 1991, p. 271). 
histórica común como justificación básica, tenía como objetivo la reconciliación hispanoamericana y el restablecimiento de relaciones culturales, educativas, diplomáticas y comerciales. Fue especialmente relevante la participación activa en la difusión del americanismo por parte de un movimiento asociacionista en alza, radicado fundamentalmente en Andalucía, Cataluña, y el norte peninsular. ${ }^{32}$

Transcurridos el IV centenario del descubrimiento, los centenarios de las primeras independencias latinoamericanas en 1910 y 1911 y el de las Cortes y la Constitución Gaditana en 1910 y 1912 como primeros espacios en los que se inicia la consolidación de este movimiento, el fenómeno hispanoamericanista alcanza un grado de visible madurez aproximadamente al comienzo de la primera guerra mundial, tras un siglo xIX donde las relaciones diplomáticas, políticas y culturales se manifiestan muy tensas entre las republicas latinoamericanas y España. Los inicios del siglo xx abren un nuevo escenario de relaciones más constructivas. A la altura de 1914 España y los países de América Latina coincidieron en su postura de neutralidad ante la guerra y comienzan a fomentar de manera conjunta la institucionalización de la fiesta de la Raza y la recuperación del 12 de octubre de 1492 como medio para romper con el aislamiento internacional y, en el caso latinoamericano, para enfrentarse simbólicamente a la influencia y expansionismo estadunidense. En efecto, desde el punto de vista identitario uno de los elementos que mejor cristalizó entre las prácticas de carácter conmemorativo implementadas fue la fiesta de la Raza, ${ }^{33}$ el mito de la raza llega a convertirse en un elemento esencial de la identidad española, matriz de una "nacionalidad compuesta" capaz de superar conflictos y tensiones identitarias. Institucionalizada como fiesta nacional española en el año 1918 a través de la ley de 15 de junio, ${ }^{34}$ la adhesión de Alfonso XIII se escenifica en 1917 al ejercer la presidencia de los actos orga-

${ }^{32}$ Sobre el asociacionismo véase Sepúlveda (1991) y Rodríguez (2004). Asociaciones como Unión Ibero-Americana (Madrid), Centro de Cultura Hispanoamericana (Madrid), Casa de América-Instituto de Economía Americana (Barcelona), Casa de América-Galicia (La Coruña), Casa de América (Santander), Centro de la Unión Ibero-Americana de Vizcaya (Bilbao), Centro de Estudios Americanistas (Valladolid), Instituto de Estudios Americanistas (Sevilla), Real Academia Hispano Americana de Ciencias y Artes (Cádiz), Real Sociedad Colombina Onubense (Huelva) o Club Palósfilo (Palos de la Frontera, Huelva) se convierten en ejes vertebradores del movimiento americanista en España (Sepúlveda, 1991, pp. 287-289).

${ }^{33}$ A través de la raza se aúnan los elementos de una comunidad imaginada: lengua, religión, tradición, pasado histórico común e incluso parentesco étnico (Marcilhacy, 2013, p. 509).

${ }^{34}$ Gaceta de Madrid, Madrid, núm. 167, 16 de junio de 1918. En Marcilhacy (2013, p. 508). 
nizados en San Sebastián por iniciativa del Ateneo Guipuzcoano y en 1919 al presidir la sesión solemne celebrada en el Ayuntamiento de Madrid el 12 de octubre de ese año. ${ }^{35}$ En este proceso de consolidación la presencia activa de la monarquía en dicha celebración será una constante en los siguientes años.

A grandes rasgos, el movimiento hispanoamericanista español y americano parte de planteamientos nacionalistas e ideológicamente de carácter liberal para ir cediendo terreno en favor de tesis nacionalistas conservadoras muy relacionadas con la fe católica, ${ }^{36}$ aunque en sus inicios desde una perspectiva liberal interesó la prosperidad que suponía el incremento de relaciones entre España y América y desde un liberalismo de corte más conservador resultaba retrospectivo y retórico en cuanto a la memoria de gestas como la conquista y la evangelización de Indias (Moreno, 2009, p. 135). Marcilhacy (2010, pp. 585-587) apunta a la implementación de dos fases: una primera de carácter liberal, progresista, regeneradora e incluso con elementos republicanos, y otra segunda, a partir de 1910, asumida y desarrollada por la ideología más conservadora a través de la vinculación de vectores tales como el patriotismo (ideal de raza) y el hispanoamericanismo.

El americanismo formó parte integrante de las relaciones de España y América Latina desde la primera guerra mundial hasta la década de 1950, aunque la etapa de mayor vigencia de estas teorías puede ubicarse en los decenios de 1920, 1930 y 1940. Desde un prisma de mayor amplitud cronológica y meramente español los presupuestos ideológicos de la dictadura de Primo de Rivera, de Falange Española y jons o de los inicios de la dictadura franquista en mayor o menor medida y con matices diferenciadores rebosan hispanoamericanismo rentabilizando conceptos como raza, nacionalidad racial, Patria Espiritual o paternalismo, más bien "matrialismo", a través de la Madre Patria con sus implicaciones en el pensamiento sobre el colonialismo. La II República, por ejemplo, también estuvo imbuida de las ideas americanistas aunque con un tono menos esencialista y más liberal. En todo caso los elementos fundamentales del hispanoamericanismo parecen encajar con mayor naturalidad

35 Memoria de la "Unión Ibero-Americana” correspondiente al año 1917. Unión Ibero-Americana, núm. 1, Madrid, 1918, p. 37; El Ayuntamiento de Madrid. Unión Ibero-Americana, núm. 18, 1919, pp. 6-9. Repositorio uniA, España, http://dspace.unia.es. Véase Marcilhacy (2010, 2011, pp. 131-148).

36 En este apartado seguimos las tesis del profesor e investigador de la UNAM Ricardo Pérez Monfort respecto a las bases ideológicas del movimiento (Pérez, 1990, 1994, pp. 343-383, 2013). Véase también Moreno (2009); Marcilhacy (2010, 2013). 
dentro de presupuestos ideológicos conservadores de carácter nacionalista, a ambos lados del Atlántico, aunque en opinión de Marcilhacy (2013) el esquema ideológico americanista presentase elementos consensuales e inclusivos, entre otras causas -aparte de las ideológicas- por la proyección hacia una comunidad racial transnacional (Marcilhacy, 2013, pp. 514-515).

Bajo este marco, extralimitando el periodo del reinado de Alfonso XIII y tomando como hitos extremos el IV centenario (1892) y la Exposición Iberoamericana de Sevilla (1929), una parte visible de las visitas oficiales del monarca a territorios andaluces y de sus ausencias más sonadas, especialmente en su franja occidental, tuvieron en su planteamiento y planificación objetivos relacionados con el movimiento hispanoamericanista. Dentro de las celebraciones del IV centenario del descubrimiento de América en 1892, cuyo núcleo central se ubicó en los lugares colombinos y en la ciudad de Huelva, la asistencia a los actos de la familia real en octubre incluyendo al propio Alfonso, quien acompañó a la regente y a sus hermanas a la edad de seis años, se rentabilizó políticamente en clave nacionalista y también desde los intereses del entonces presidente del Consejo de Ministros Cánovas del Castillo. ${ }^{37}$ Años atrás, durante la visita oficial de Alfonso XII a Huelva a inicios de marzo de 1882 ya se planificó una visita a La Rábida y a su monasterio, para lo cual las autoridades procedieron a la instalación de un muelle provisional y al arreglo del camino de acceso al monasterio. ${ }^{38}$

Alfonso XIII tendrá una nueva ocasión de personarse en La Rábida y los lugares colombinos en su visita a Huelva del 6 al 7 de mayo de 1904; la propia prensa de la capital onubense anunciaba que no se recordaba tanta concurrencia y expectación en la ciudad desde las celebraciones del IV centenario. ${ }^{39}$ Procedente de Cádiz se tenía previsto que la primera parada del yate Giralda fuese en La Rábida, como así fue. La recepción del monarca por parte de las autoridades locales y provinciales se produjo en el histórico lugar con las correspondientes visitas al monasterio y al monumento en construcción. Aparte de este episodio el epicentro del programa de actividades durante la estancia del monarca se situó en la ciudad de Huelva, donde se cumplieron

${ }^{37}$ Para profundizar sobre el IV centenario véase (Bernabéu, 1987). Sobre el desarrollo del movimiento hispanista en Huelva (Márquez, 2011, pp. 21-58). Por otra parte la polémica política suscitada por el protagonismo de Cánovas del Castillo en los actos es una materia de análisis que supera los objetivos de este artículo.

${ }^{38}$ La Provincia, Huelva, 28 de febrero de 1882 y 2 de marzo de 1882.

${ }^{39}$ La Provincia, Huelva, 6 de mayo de 1904. 
con todas las etapas del canon preestablecido para este tipo de viajes regios. Entre las peticiones que recibió el rey y los miembros del gobierno destaca la de la Sociedad Colombina Onubense, de la que era presidente honorífico Alfonso XIII, ${ }^{40}$ que solicitaba ayuda económica para concluir las obras de restauración del monasterio y del monumento a la fe descubridora erigido junto al mismo, ${ }^{41}$ con escaso éxito.

La puesta en práctica de las redes de sociabilidad bidireccionales entre la corona y las elites locales se llevaba a cabo, entre otros elementos, a través de este tipo de sociedades de carácter eminentemente burgués. El papel preponderante de la Sociedad Colombina Onubense junto al de instituciones, representantes políticos y otros líderes de la sociedad clientelar propia de la Restauración se despliega en las visitas regias a Huelva de manera repetitiva, donde de manera simbólica el monarca junto a la sociedad y sus miembros de mayor visibilidad (Marchena Colombo, Sundheim...) escenifican el ideal americanista en La Rábida y los lugares colombinos. Como se ha apuntado, ya desde la época de Alfonso XII y especialmente tras las celebraciones del IV centenario La Rábida se convierte en un lugar común en la planificación de las agendas de las visitas oficiales a la zona, se instrumentaliza como uno de los santuarios del ideal americanista y como un espacio nacional de primer orden, ya que se logra rentabilizar a la hora de promocionar mitos y símbolos fundacionales vinculados con la relación histórica entre España y América Latina, todo ello convenientemente apuntalado a través de la erección de monumentos dedicados a la fe descubridora.

Sin lugar a dudas el movimiento hispanoamericanista recibió un importante impulso y respaldo por parte de la corona española en las celebraciones de la independencia de Argentina en 1910, para lo que el rey envió como delegada personal a su tía, la infanta Isabel (Moreno, 2013a, p. 336). En este contexto dentro de las diferentes publicaciones de corte hispanoamericanista, en las que las actividades de Alfonso XIII son cubiertas muy recurrentemente, se inicia un debate de largo recorrido sobre la idoneidad de la organización de una visita oficial del monarca a Latinoamérica, en una etapa de su reinado

${ }^{40}$ Cargo honorífico que heredó de su padre, ya que Alfonso XII se incluye como socio honorífico en el acta fundacional de la sociedad de 21 de marzo de 1880 (Márquez, 2011, p. 26).

${ }^{41}$ La Provincia, Huelva, 6 de mayo de 1904. 
donde el recurso de la visita real fue muy rentabilizado y uno de los objetivos estratégicos para la corona era la proyección exterior. ${ }^{42}$

Dentro del mito de la nacionalidad racial la lealtad dinástica desempeñaba un papel central en las primeras décadas del siglo xx. España debía ejercer el liderazgo del movimiento americanista con su monarca a la cabeza, y Alfonso XIII personificaba y simbolizaba al movimiento; los americanistas subrayaban constantemente su papel como "rey de la raza" y factor aglutinador y de unidad para la comunidad hispánica (Marcilhacy, 2013, p. 515). Contradictoriamente Alfonso XIII, el rey viajero, nunca llegó a realizar la visita oficial a América Latina, tan deseada por los hispanoamericanistas. Desde palacio se acudió constantemente a otras personas del entorno familiar de Alfonso para representar a España en acontecimientos como el ya relatado del centenario de las primeras independencias, o la conmemoración en Chile del centenario del descubrimiento del Estrecho de Magallanes (1919), a la que se envió al infante Fernando en cuyo viaje visitó también Argentina, Uruguay, Panamá y Perú (Márquez, 2016, p. 10). Desde la intelectualidad hispanoamericanista se lamentó constantemente la ausencia de esta visita oficial. Para Francos Rodríguez, por ejemplo -uno de los acompañantes del infante Fernando en el viaje de 1919-, aparte de los tradicionales argumentos discursivos de colaboración y amistad mutua en dicho viaje, no se concretaron líneas políticas de colaboración que a su juicio sí que se hubiesen podido explorar con la presencia de Alfonso XIII en América (Francos, 1921).

Por otra parte, el protagonismo del movimiento se va consolidando progresivamente en ciudades como Madrid, Barcelona, Bilbao, Santander, La Coruña o San Sebastián en detrimento de localidades andaluzas con una importante vinculación histórica con el continente americano como Huelva, Sevilla o Cádiz. Aunque al amparo de la gran cantidad de centenarios que se suceden a comienzos del siglo xx surge una nueva oportunidad de estrechar lazos con América Latina a través del centenario de las Cortes de Cádiz y de la Constitución de 1812, con nutrida presencia de representaciones diplomáticas latinoamericanas invitadas para conmemorar la participación y aportaciones de los diputados de ultramar en las Cortes.

${ }^{42}$ El Rey de España y los pueblos iberoamericanos. Unión Ibero-Americana, núm. 8, 1907, p. 6; El viaje del rey a América. Unión Ibero-Americana, núm. 10, 1907, p. 5. Repositorio UNIA, España, http://dspace.unia.es (Marcilhacy, 2013, p. 515). 
Estas celebraciones en Cádiz trataron de consolidar los primeros pasos ya dados para estrechar lazos de concordia, unidad y reconciliación entre España y sus antiguas colonias. Entre otros actos se descubrieron lápidas dedicadas a los diputados doceañistas procedentes de los entonces territorios ultramarinos o se organizaron tertulias de carácter histórico y cultural en las que intelectuales de ambos lados del Atlántico debatieron sobre muy diversos temas (Pecci y Moreno, 2012, p. 182). La organización de esta celebración puede ejemplificar la iniciativa de la sociedad civil a escala local y del posicionamiento en un segundo plano de los poderes centrales y de la monarquía, además, en este caso el protagonismo del alcalde Cayetano del Toro y del entonces senador Rafael de Labra contribuyó a darle a la celebración un marcado carácter americanista (Marcilhacy, 2013, pp. 516-517). Alfonso XIII, sin embargo, se limitó en exclusiva a recibir en Madrid a las delegaciones diplomáticas latinoamericanas enviadas para participar en las celebraciones de 1912, esgrimiendo el luto por la muerte de su hermana, la infanta María Teresa, lo que provocó retrasos en el calendario previsto y finalmente la ausencia del rey (Moreno, 2003a, p. 224). Esta circunstancia resultó decepcionante para las elites y para el pueblo de Cádiz. La prensa gaditana, al igual que sus autoridades, imploraron la presencia del monarca hasta el último momento. En esta línea se lamentaba a posteriori el Diario de Cádiz: ¿¿Qué puede haber más elevado para un rey español que la glorificación de la nueva Covadonga, que eso fue Cádiz?" ${ }^{43}$ Alfonso XIII a su vez tampoco estuvo presente en la Asamblea de Asociaciones y Corporaciones Americanistas celebrada en La Rábida del 31 de mayo al 3 de junio de 1912 (Márquez, 2011, p. 28).

Tras estos desencuentros la conjunción de los elementos: Alfonso XIII, visita real, Andalucía y movimiento americanista, presenta un éxito muy escaso durante los siguientes años, al menos en cuanto a acontecimientos y celebraciones relevantes. Pero, por otra parte, fue una etapa de desarrollo y crecimiento del movimiento hispanoamericanista a ambos lados del Atlántico. Hasta 1926, en plena dictadura del general Primo de Rivera, no se produjo la siguiente visita de Alfonso XIII a Huelva y los lugares colombinos, en este caso con motivo del regreso de la tripulación del vuelo del Plus Ultra (Marcilhacy, 2006, pp. 213-241). Dicha travesía aérea, planteada simbólicamente como rememoración del primer viaje colombino y como operación de prestigio desde el gobierno español, salió de Palos de la Frontera el 22 de enero de

${ }^{43}$ Diario de Cádiz, Cádiz, 26 de septiembre de 1912. En Moreno (2003a, p. 189). 
1926 para llegar a Buenos Aires el 7 de febrero haciendo escalas en Puerto de la Luz, Puerto Praia, Fernando Noronha, Recife, Río de Janeiro y Montevideo (Márquez, 2016). Alfonso XIII se desplazó a Huelva y La Rábida para recibir a su regreso a los aviadores -Franco, Ruiz de Alda, Durán y Rada-, quienes volvieron vía marítima. Durante las celebraciones en los lugares colombinos el monarca expresaba protocolariamente a los representantes diplomáticos de América Latina su satisfacción por el éxito del viaje, en una intervención que sintetiza el discurso americanista (regeneracionismo, patriotismo...), incluyendo su proyección en la política internacional: ${ }^{44}$

Me satisface hacer este recibimiento a mis oficiales aviadores que han ido, no ha descubrir, sino a llevar allí el corazón de España que se han traído unido al de América. La hazaña de mis oficiales demuestra lo que puede conseguir la raza hispana [...] Los pueblos que desean existir y vivir prósperamente, han de rendir culto al sentimiento perenne de la Patria [...] España os descubrió [...] luego enfermó; pero ahora ha vuelto a renacer y ahí va ese avión mensajero de su grandeza; si necesitaras algo de España lo tendrás cuanto antes, porque España es para el Nuevo Mundo lo que fue siempre. A vosotros, americanos, pertenece el porvenir: unidos con España llevaremos la paz a Europa, labor ésta más segura que la que se pretende hacer en Ginebra, jugándose o disputándose los puestos que se daban allí. ${ }^{45}$

En efecto, el gobierno de Primo de Rivera con el beneplácito del monarca Alfonso XIII alimentó una serie de ambiciones en política exterior en el contexto posterior a la primera guerra mundial en las que los puntos nodales se situaron en Marruecos y en América. Primo de Rivera pretendió hacer de España el portavoz de un hipotético bloque de naciones hispánicas en la nueva Liga de las Naciones, aunque los intentos de recibir un apoyo unitario para este fin resultaron infructuosos (Marcilhacy, 2016, p. 157). Dentro de esta línea política los últimos años del reinado de Alfonso XIII experimentaron un apreciable auge en el interés de palacio hacia el movimiento hispanoamericanista al amparo de los preparativos de la Exposición Iberoamericana, 239-276)

${ }^{44}$ Sobre el perfil internacional y diplomático de Alfonso XIII véase Niño (2003, pp.

${ }^{45}$ Fecha memorable. La Rábida. Revista Iberoamericana, núm. 141, 1926, p. 12. Repositorio Institucional UNIA, España, http://dspace.unia.es 
celebrada entre 1929 y 1930 en Sevilla. ${ }^{46}$ La casa real participó en la organización de un acto que suponía la culminación del hispanoamericanismo en las primeras décadas del siglo xx y una oportunidad estratégica de proyección internacional para el país y el régimen primorriverista. El planteamiento y la fastuosidad del evento simbolizó la celebración de la plurisecular vocación imperial española, que reivindicaba el estatus de madre y tutora de una gran familia de pueblos ya independientes (Marcilhacy, 2016, p. 157). Como ya se ha puntualizado un hecho sintomático de la apuesta de la corona por un acontecimiento plenamente hispanoamericanista fue la frecuencia de las visitas oficiales a Sevilla que se incrementó notablemente hasta llegar a las 32 visitas entre 1909 y 1929, sobre todo en la segunda mitad de la década de 1920 para supervisar e inaugurar las obras ya culminadas para la exposición (Braojos, 1992). Uno de los centros neurálgicos de la exposición era el parque de María Luisa, jardines donados por la infanta María Luisa Fernanda a la ciudad en 1893 (Rodríguez, 2006, p. 160), lo que potenciaba la vinculación simbólica de la corona y la dinastía con dicho acontecimiento. Por otra parte, los organizadores del acto eran el Ayuntamiento de Sevilla, un comité ejecutivo, un comisario regio, cargo ocupado por el conde de Urbina (1920-1922), el conde de Colombí (1923-1925) -entonces alcalde de Sevilla- y por José Cruz Conde ${ }^{47}$ a partir de diciembre de 1925 , quien además ejerció el cargo de director de la Exposición Iberoamericana.

Alfonso XIII, aparte de presidir los actos centrales de este evento, fue el presidente de honor del comité nacional, formado, entre otros, por los presidentes de las repúblicas de América y por los embajadores y representantes diplomáticos de los países americanos y Portugal. Desde el punto de vista diplomático se escenifica en 1929 un hito en el estrechamiento de lazos de amistad y alianza con el ámbito latinoamericano, y la corona apuesta por un acontecimiento plenamente hispanoamericanista, al menos desde un plano diplomático, ya en fechas cercanas al final del reinado en 1931. Al margen de los actos inaugurales y de clausura, del papel del rey como anfitrión del evento, de las propias jornadas de la exposición, y de las polémicas en la prensa sobre el desequilibrio de protagonismo mediático entre la corona

${ }^{46}$ Sobre la exposición y el papel de Alfonso XIII en la misma véase Braojos (1992); Lemus (1987); Rodríguez (2006).

${ }^{47}$ José Cruz Conde fue alcalde y jefe de la Unión Patriótica de Córdoba, en Sevilla hacia 1925 ocupaba el cargo de gobernador civil cuando fue nombrado comisario regio (Lemus, 1987, p. 90). 
y Primo de Rivera; lo que ha preponderado en los discursos oficiales es la decidida voluntad y acción de Alfonso XIII para que el certamen finalmente pudiese ejecutarse (visitas a las obras, contactos diplomáticos como con Estados Unidos...) y que dicha celebración se produjese en Sevilla, frente a otras candidaturas como Madrid y Bilbao -ciudad a la que finalmente se le concedió la celebración de una Exposición Internacional de Industria y Comercio. ${ }^{48}$

\section{CONSIDERACIONES FINALES}

Dentro de las ceremonias monárquicas de la época, el canon de las visitas oficiales de Alfonso XIII a territorios andaluces responde a una programación bien planificada, con puntos de encuentro muy definidos, escenificados e incluso ritualizados. Especialmente durante el primer periodo del reinado (1902-1913) la estrategia del viaje regio oficial ocupó un lugar central en la política de nacionalización de las masas, y se utilizó este recurso de manera intensa y sistemática. En líneas generales la visita oficial estaba llena de episodios recurrentes que contenían mensajes nacionalistas, donde la monarquía escénica o monarquismo banal aparentemente parecen dar sus frutos en cuanto a la consolidación del discurso hegemónico nacionalista de su tiempo. Se trataba de presentar al monarca como representante de la nación, personificación ante el pueblo de una idea tan abstracta como el Estado o la nación, para crear una relación mucho más personal y cercana con la gente. Progresivamente la búsqueda de réditos en política interna e internacional desde una perspectiva latinoamericana parece instalarse en las estrategias de palacio.

En general el planteamiento de estructurar la idea nacional desde la referencia exterior de América Latina comienza a construirse desde abajo hacia arriba e incluso desde la periferia hacia el centro, con un indudable protagonismo de regiones como Andalucía y Cataluña. No puede considerarse, por tanto, como una imposición del Estado, de las elites vinculadas a los poderes centralizadores o de la corona; al contrario, el fomento del ideal

${ }^{48}$ El recorrido histórico desde la gestación de la propia idea de la Exposición, los aplazamientos y dificultades de los años previos y el papel de la corona en la elección de Sevilla se manifiesta desde un discurso de naturaleza oficialista en la prensa de la época. $A B C, 10$ de mayo de 1929, Sevilla, pp. 3-4. 
americano parte de múltiples identidades -local, regional, nacional e incluso panhispánica (Marcilhacy, 2013, p. 504)- integrantes del imaginario español de manera inclusiva y complementaria. Desde este enfoque inclusivo y desde la perspectiva del potencial que la monarquía española mostró en la época de Alfonso XIII, en cuanto a su capacidad nacionalizadora, y siguiendo la tónica de otras monarquías del entorno europeo (Moreno, 2009, p. 145), el rey se muestra simbólicamente como un elemento fundamental para el movimiento americanista, como el rey de la Raza o de la nacionalidad racial hispánica.

Aludimos a ciertas limitaciones y ausencias del monarca como agente nacionalizador, entre las que destaca su segundo plano en los actos de 1910 y de 1912 o la falta de un viaje oficial al continente americano durante el reinado para unir lazos políticos, diplomáticos y comerciales entre estados. Los viajes del rey fueron en la propia península, con una visión nacionalizadora y dirigida hacia objetivos de política interna, en especial durante la primera etapa del reinado (1902-1913).

A partir de 1917 y 1918 Alfonso XIII consolida su papel simbólico como rey de la raza; la monarquía adquiere un lugar central en el movimiento hispanoamericanista una vez que cobran protagonismo los elementos patrióticos, raciales y conservadores. Su liderazgo simbólico durante las primeras décadas del siglo xx se muestra entre otros elementos en el recurso de la visita real en actos y conmemoraciones de contenido americanista, con especial relevancia en los territorios andaluces por su simbología histórica (especialmente en el triángulo Huelva/Sevilla/Cádiz), donde encontramos éxitos, fracasos, fortalezas y limitaciones. Conforme avanza el reinado el 12 de octubre se consolida como fiesta nacional y la perspectiva de la celebración de la Exposición Iberoamericana de Sevilla comienza a percibirse como una gran oportunidad de proyección internacional dentro de la línea política planteada por el régimen primorriverista. En estas circunstancias el papel central de Alfonso XIII dentro del movimiento hispanoamericanista experimenta un visible salto cualitativo, en una etapa en la que internamente la imagen y posición de la corona española está cada vez más en entredicho, como se comprobaría en 1931. Para Michael Billing el concepto de nacionalismo/monarquismo banal comporta una doble dimensión: una acción política deliberada por parte del Estado que tuvo éxito, y a partir de ahí una acción colectiva impulsada más allá de los poderes públicos (Billing, 1995). Aparte del éxito coyuntural o en el corto plazo, diversas implicaciones políticas -además de otros factores-, como la salida dictatorial en la etapa final del reinado, impidieron que la figura del monarca 
y de su persona pudiese convertirse en un símbolo nacional indiscutido $y$, desde un plano internacional e hispanoamericanista en una figura indiscutida dentro de un movimiento que continuó su desarrollo histórico al margen de Alfonso XIII a partir de 1931.

Por último, el principal aporte historiográfico de este estudio se dirige hacia la articulación de las relaciones entre los poderes centrales y periféricos a la hora de apostar por el movimiento hispanoamericanista como política nacionalizadora, desde un estudio de caso centrado en los viajes reales a la región de Andalucía. Como se ha comentado el movimiento hispanoamericanista presenta un fuerte enraizamiento regional dentro de la geografía española, en la que el peso específico de Andalucía irá perdiendo terreno aunque las visitas reales ligadas a efemérides o acontecimientos como la exposición de Sevilla de 1929 mantienen a estos territorios en un primer plano dentro de las actividades del movimiento americanista. Entre las limitaciones visibles del estudio se encuentran una serie de cuestiones sobre las que necesariamente habría que profundizar. Entre ellas, la imbricación entre Alfonso XIII, el movimiento hispanoamericanista, y la visión y los discursos de intelectuales adheridos al movimiento y las asociaciones a ambos lados del Atlántico, por ejemplo, en el debate sobre el posible viaje oficial de Alfonso XIII al continente americano.

En otro orden de cosas, el papel del rey durante la década de 1920 en la preparación y escenificación de la exposición de 1929 es otro tema fundamental sobre el que necesariamente habría que profundizar, especialmente en lo referente a los aspectos discursivos, aunque la amplitud de estos temas requiere un tratamiento más profundo y analizar cuestiones que merecen un enfoque monográfico de mayor amplitud.

\section{LISTA DE REFERENCIAS}

Alfaro, P. (1921). Crónica del viaje de S. M. el rey D. Alfonso XIII a Málaga: los días 21 y 22 de mayo de 1921. Málaga: Imp. Ibérica.

Álvarez, J. (2001). Mater Dolorosa. La idea de España en el siglo XIX. Madrid: Taurus.

Barral, M. (2012). A visita de Isabel II a Galicia en 1858. Monarquía e provincialismo ao servizo de nacionalización. Santiago de Compostela: Sotelo Blanco Edicions.

Beramendi, J., Máiz, R. y Núñez, X. M. (eds.) (1995). Nationalism in Europe. Past and present. Santiago de Compostela: Universidad de Santiago de Compostela. 
Bernabéu, S. (1987). 1892: El IV Centenario del Descubrimiento de América en España. Madrid: CISC.

Billing, M. (1995). Banal nacionalism. Londres: Sage.

Braojos, A. (1992). Alfonso XIII y la Exposición Iberoamericana de Sevilla de 1929. Sevilla: Universidad de Sevilla.

Canal, J. y Moreno, J. (eds.) (2009). Historia cultural de la política contemporánea. Madrid: CEPC.

Carasa, P. (2007). La reina en la Ciudad: usos de la historia en la visita de Isabel II a Valladolid en 1858. Valladolid: Ayuntamiento de Valladolid.

Fernández, M. C. (2005). Imágenes y representaciones del poder: las visitas reales en la Sevilla del siglo XIX. (Tesis de doctorado). Sevilla: Universidad de Sevilla, España.

Fernández, M. C. (2007). Sevilla y la monarquía. Las visitas reales en el siglo XIX. Sevilla: Universidad de Sevilla.

Fernández, M. (1977). Historia del reinado de Alfonso XIII. Barcelona: Montaner y Simón, S. A.

Francos, J. (1921). Huellas españolas: Impresiones de un viaje por América. Madrid: Editorial América.

Gaona, M. (1904). Crónica descriptiva de la visita de S. M. el rey Don Alfonso XIII en mayo de 1904 a la ciudad de Cádiz. Jerez de la Frontera: Est. Tip. de M. Martín.

Granja, J. L., Anguera, P. y Beramendi, J. (eds.) (2001). La España de los nacionalismos y las autonomías. Madrid: Síntesis.

Lemus, E. (1987). La Exposición Ibero-Americana a través de la prensa (1923-1929). Sevilla: Mercasevilla, S. A.

Marcilhacy, D. (2006). La Santa María del aire. El vuelo trasatlántico del Plus Ultra (Palos-Buenos Aires, 1926), preludio de una reconquista espiritual de América. Cuadernos de Historia Contemporánea, 28, 213-241. Recuperado de https://revistas. ucm.es/index.php/CHCO/article/view/CHCO0606110213A

Marcilhacy, D. (2010). Raza hispana. Hispanoamericanismo e imaginario nacional en la España de la Restauración. Madrid: CEPC.

Marcilhacy, D. (2011). Las fiestas del 12 de octubre y las conmemoraciones americanistas bajo la restauración borbónica: España frente a su pasado colonial. Revista de Historia Jerónimo Zurita, 86, 131-148. Recuperado de https://ifc.dpz.es/ publicaciones/ebooks/id/3187

Marcilhacy, D. (2013). América como vector de regeneración y cohesión para una España plural: "La Raza" y el 12 de octubre, cimientos de una unidad compuesta. Hispania, LXIII(244), 501-524. DOI: 10.3989/hispania.2013.015 
Marcilhacy, D. (2016). Las figuras de "la Raza": de la España Mayor a la Comunidad Iberoamericana, perspectivas (post)imperiales en el imaginario español. Historia y Política: Ideas, Procesos y Movimientos Sociales, 35, 145-174. DoI: 10.18042/hp.35.07

Márquez, R. (2011). Huelva y América. Cien años de americanismo. Revista La Rábida (1911-1933). En Márquez, R. (ed.), Huelva y América. Cien años de americanismo (pp. 21-58). Sevilla: Universidad Internacional de Andalucía.

Márquez, R. (ed.) (2016). De Palos al Plata. El vuelo del Plus Ultra a 90 años de su partida. Sevilla: Universidad Internacional de Andalucía.

Mateos, C. (2003). La conmemoración del primer centenario del sitio, las Cortes y la Constitución de Cádiz. Cuadernos de Ilustración y Romanticismo, 11, 171-192. DoI: 10.25267/Cuad_Ilus_Romant.2003.i11.08

Morales, A., Fusi, J. P. y Blas, A. de (coords.) (2013). Historia de la nación y del nacionalismo español, Barcelona: Galaxia Gutenberg.

Moreno, J. (coord.) (2003). Alfonso XIII. Un politico en el trono. Madrid: Marcial Pons.

Moreno, J. (2003). Memoria de la nación liberal: el primer centenario de las Cortes de Cádiz. Ayer, 52, 207-236. Recuperado de https://www.ucm.es/data/cont/docs/2972013-07-29-6-03.pdf

Moreno, J. (coord.) (2007). Construir España: nacionalismo español y procesos de nacionalización. Madrid: CEPC.

Moreno, J. (2009): Mitos de la España inmortal. Conmemoraciones y nacionalismo español en el siglo xx. En C. Forcadell, P. Salomón e I. Saz (eds.), Discursos de España en el siglo xx (pp. 123-146). Valencia: Universidad de Valencia.

Moreno, J. (2013a). Alfonso el Regenerador. Monarquía escénica e imaginario nacionalista español, en perspectiva comparada (1902-1913). Hispania, 73(244), 319-348. DOI: 10.3989/hispania.2013.009

Moreno, J. (2013b). Monarchia in scena e discorsi nazionalliste nella Spagna del Rigenerazionismo (1902-1913). Memoria e Ricerca, 42, 107-126. DOI: 10.3280/ MER2013-042007

Niño, A. (2003). El rey embajador: Alfonso XIII en la política internacional. En J. Moreno (coord.), Alfonso XIII. Un político en el trono (pp. 239-276). Madrid: Marcial Pons.

Núñez, V. M. (2016). Las visitas reales de Alfonso XIII a Andalucía y Canarias. Entre España y América Latina: ¿Una oportunidad perdida? En M. Barral (ed.), Alfonso XIII visita España. Monarquía y nación (pp. 221-243). Granada: Comares.

Núñez, V. M. (en prensa). Ceremonias reales y dimensión cultural. Monarquía y Nación a través de la visita de Isabel II a Andalucía en 1862. Hispania. 
Pecci, D. y Moreno, J. (2012). La celebración del centenario de la Constitución de 1812: una fiesta de las elites entre la nostalgia y el regeneracionismo. Trocadero, 24, 181-196.

Pérez, R. (1990). Breve antología de documentos hispanistas (1931-1948). México: Secretaría de Educación Pública/Centro de Investigaciones y Estudios Superiores de Antropología Social.

Pérez, R. (1994). Indigenismo, hispanismo y panamericanismo en la cultura popular mexicana de 1920 a 1940. En R. Blancarte (coord.), Cultura e identidad nacional (pp. 343-383). México: FCE.

Pérez, R (2013). Miradas, esperanzas y contradicciones. México y España, 1898-1948. Santander: Universidad de Cantabria.

Pike, F. B. (1971). Hispanismo, 1898-1936: Spanish conservatives and liberals and their relations with Spanish America. Notre Dame: University of Notre Dame Press.

Rodríguez, M. (2004). De la moda de los centenarios a un aniversario. El 12 de octubre en España. En E. Pani y A. Salmerón (coords.), Conceptualizar lo que se ve: François-Xavier Guerra historiador. México: Instituto Mora.

Rodríguez, E. (2006). La Exposición Iberoamericana de Sevilla. Sevilla: Ayuntamiento-ICAs.

Rubí, G. (2013). La Corona y la Nación: las visitas reales como política pública. En P. Gabriel, J. Pomés y F. Fernández (eds.), España Res Publica. Nacionalización española e identidad en conflicto (siglos XIX y XX) (pp. 67-78). Granada: Comares.

Sepúlveda, I. (1991). Medio siglo de asociacionismo americanista español (1885-1936). Espacio, Tiempo y Forma. Serie v, 4, 271-290.

Sepúlveda, I. (2002). De intenciones y logros: fortalecimiento estatal y limitaciones del nacionalismo español en el siglo xix. Amnis Revue de Civilisation Contemporaine Europes/Ameriques, 2. DoI: 10.4000/amnis.137

Sepúlveda, I. (2005). El sueño de la madre patria: hispanoamericanismo y nacionalismo. Madrid: Marcial Pons.

Sepúlveda, I. (2013). América en el nacionalismo español. El hispanoamericanismo. En A. Morales, J. P. Fusi y A. de Blas (coords.), Historia de la nación y del nacionalismo español (pp. 1031-1047). Barcelona: Galaxia Gutemberg.

Taibo, C. (coord.) (2007). Nacionalismo español: esencias, memorias e instituciones. Madrid: Libros de la Catarata.

Urbano, R. (1904). La visita regia. Crónica de la estancia de S. M. el rey Don Alfonso XIII en la Muy Hospitalaria Ciudad de Málaga. Málaga: Tip. de los Hijos de J. Giral. [Edición facsimilar en Málaga, Universidad de Málaga, 2000]. 
Utrera, R. (1999). La imagen de Andalucía en la Colección Real de fotografía del Archivo General de Palacio. PH Boletín del Instituto Andaluz del Patrimonio Histórico, VII(28), 179-184.

\section{OTRAS FUENTES}

\section{Hemerografía}

La Rábida. Revista Iberoamericana, Huelva (1911-1931).

La Provincia, Huelva (1882-1926). Números sueltos.

Diario de Cádiz, Cádiz (1912). Números sueltos.

$A B C$, Sevilla (1929). Números sueltos. 